Revista Destaques Acadêmicos, Lajeado, v. 12, n. 2, 2020. ISSN 2176-3070

DOI: http://dx.doi.org/10.22410/issn.2176-3070.v12i2a2020.1909

http://www.univates.br/revistas

\title{
COMPORTAMENTO DE RISCO E A CONTRIBUIÇÃO DA PSICOLOGIA PARA A REDUÇÃO DOS ACIDENTES DE TRÂNSITO: UMA REVISÃO DA LITERATURA
}

\author{
Neusa Maria Zanon ${ }^{1}$, Luciane De Fátima Rotth Brisotto ${ }^{2}$
}

\begin{abstract}
Resumo: Este artigo tem o objetivo de identificar os principais estudos que descrevem as causas, as consequências e a contribuição da psicologia em relação aos acidentes de trânsito, visto o elevado número de acidentalidade nas estradas de todo o Brasil, na maioria considerados gravíssimos devido ao alto índice de mortes e sequelas dos envolvidos. Através da leitura das bibliografias encontradas, verificou-se o quanto o fator humano implica nas causas e consequências dos acidentes de trânsito, principalmente no que diz respeito à conduta e ao comportamento dos condutores, sendo que, referente a estes, nota-se que prevalece a desatenção e o excesso de confiança. Como estudado, o trânsito não é constituído somente de condutores de veículos, mas também de tudo e todos que se envolvem no espaço destinado para a circulação e o movimento. Dentro deste ambiente, outro elemento que também circula em grande número e predispõe significativo índice de risco é o pedestre, o qual também tem regras e normas a seguir. De tal modo, é possível às políticas públicas de transportes e circulação, através de um trabalho multidisciplinar no qual a psicologia também contribua, procurar desenvolver ações que priorizem o espaço urbano, com o objetivo de proporcionar um ambiente harmônico e democrático. Este trabalho pode visar, ainda, possibilidades de uso e incentivos voltados aos outros meios de transportes, objetivando mais fluidez e segurança no trânsito.
\end{abstract}

Palavras-chave: Acidente. Comportamento. Psicologia. Trânsito.

1 Neusa Maria Zanon, graduada em Psicologia pela Universidade de Passo Fundo, estudante do curso de Pós Graduação de Psicologia do Trânsito na Universidade do Vale do Taquari Univates, Lageado/RS. Email: psiconm@hotmail.com.

2 Luciane De Fátima Rotth Brisotto, graduada em Psicologia pela Universidade do Vale do Rio dos Sinos (UNISINOS), Psicóloga Perita em Trânsito pela Universidade Luterana do Brasil (ULBRA), Especialista em Planejamento e Gestão de Trânsito pelo Centro Universitário de Maringá (UNICESUMAR), Especialista em Psicologia Clínica Cognitivo-Comportamental pela Universidade de Araraquara (UNIARA), e Professora convidada da Universidade do Vale do Taquari - Univates, Lajeado/RS. Orientadora. Email: lucianebrisotto@gmail.com. 


\section{INTRODUÇÃO}

A proposta deste trabalho é fazer uma revisão bibliográfica de estudos existentes que discorrem sobre acidentes de trânsito ou infrações e estão relacionados às condições psicológicas dos condutores. Assim, este tem como objetivo identificar os principais estudos que descrevem as causas, as consequências e a contribuição da psicologia em relação aos acidentes de trânsito. Para, a partir disso, entender os motivos que levam um indivíduo a se colocar em risco e expor outras pessoas à mesma situação quando está na direção de um automóvel.

Para Tebaldi e Ferreira (2004), o fator humano é o principal causador do elevado número de acidentes. No entanto, os indivíduos precisam ser analisados inseridos em um contexto, uma vez que cada um tem determinada história, personalidade, interesses e necessidades que busca satisfazer, o que gera conflitos no trânsito, já que cada qual compreende as regras estabelecidas conforme a visão de mundo que possui. Devido a este fator, algumas pessoas agem conforme a lei e outras não. E é na busca da satisfação que acontecem atitudes e comportamentos que podem colocar em risco a segurança no trânsito e esse determinante acaba estabelecendo o modo como o trânsito acontece.

De acordo com Oshira (2017a), os principais riscos comportamentais que causam acidentes no trânsito são sete: excesso de confiança do motorista, falta de atenção, fadiga do condutor, excesso de velocidade, pressão do tempo, distância entre veículos e ultrapassagem perigosa. É por isso que se considera que $90 \%$ dos acidentes são causados por falha humana. Assim, "o motorista tem papel fundamental na direção, pois está sob efeito de elementos internos e externos como a saúde física, maturidade de discernimento, via e meio ambiente, análise de informações, tomadas de decisões, entre outros" (OSHIRA, 2017a, p. 1).

Portanto, a presente pesquisa se justifica por buscar compreender os fatores comportamentais que podem ampliar o risco de acidentes e analisar quais contribuições a psicologia pode oferecer no sentido de reduzir de forma considerável estes comportamentos. Como se sabe, atualmente, o trabalho dos psicólogos em relação ao processo de formação dos condutores resume-se à seleção de pessoas aptas à condução de um veículo, impedindo que aqueles com perfil inadequado possam oferecer risco à segurança no trânsito. Contudo, cabe entender se este trabalho não poderia ser ampliado no sentido de utilizar os estudos e análises da psicologia como forma educacional e instrutiva desde o ensino regular até a formação de futuros condutores.

A fim de desenvolver este estudo, o trabalho foi dividido em capítulos. Inicialmente, será apresentada a metodologia adotada para a análise, seguida do desenvolvimento do trabalho em dois capítulos. O primeiro trata das causas e consequências do comportamento de risco no trânsito, abordando os principais fatores deste comportamento, como o excesso de confiança do motorista, o 
excesso de velocidade, a distância entre os veículos, a ultrapassagem perigosa e, um dos maiores problemas enfrentados no País no que se refere ao trânsito, a ingestão de bebidas alcoólicas. Em seguida, o próximo capítulo aborda o papel que a psicologia pode representar para reduzir potencialmente os acidentes de trânsito, tratando também da importância da educação para o trânsito. Por fim, a conclusão apresenta o fechamento do trabalho, com as considerações finais acerca do tema.

\section{COMPORTAMENTO DE RISCO NO TRÂNSITO: CAUSAS E CONSEQUÊNCIAS}

A ocorrência de acidentes de trânsito no Brasil crescem ano a ano, isso em decorrência do aumento no fluxo de veículos nas estradas e rodovias e, principalmente, pelo fator humano, que pode envolver aspectos de risco tanto físicos, quanto sociais e psicológicos dos condutores. Para tanto, a presente pesquisa tem como objetivo identificar os principais estudos que descrevem as causas, as consequências e a contribuição da psicologia em relação aos acidentes de trânsito.

A metodologia deste trabalho, devido à sua finalidade, classifica-se como uma pesquisa descritiva. Isso porque, como coloca Gil (2008, p. 28), este tipo de pesquisa "têm como objetivo primordial a descrição das características de determinada população ou fenômeno ou o estabelecimento de relações entre variáveis". Para tanto, por meio deste trabalho, busca-se fazer uma análise sobre os motivos que influenciam o comportamento de risco de alguns condutores de veículos, bem como a relação com os fatores psicológicos destes.

Da mesma forma, devido a esta análise sobre o tema, no que se refere à abordagem do estudo, este se encaixa como uma pesquisa qualitativa. De acordo com Neves (1996, p. 1), esta metodologia "compreende um conjunto de diferentes técnicas interpretativas que visam a descrever e a decodificar os componentes de um sistema complexo de significados". Por fim, o delineamento da pesquisa refere-se à uma pesquisa bibliográfica, já que foram consideradas as conceituações e ponderações de outros teóricos tanto da área de segurança no trânsito quanto na área de psicologia a fim de entender a correlação de ambos e compreender com profundidade o tema.

A referida pesquisa foi feita em sites renomados que abordam o tema da segurança no trânsito no Brasil, para tanto, foram considerados apenas sites na língua portuguesa. Como forma de pesquisa dos artigos online, foram utilizadas as seguintes palavras descritoras (palavras-chave): Acidente; Comportamento; Psicologia; Trânsito. Após a pesquisa, foram selecionados os artigos mais condizentes com o presente trabalho e que fossem atuais (10 anos), já que este é um tema vigente. 


\subsection{Acidentes de trânsito e o comportamento humano}

Entre as principais causas de morte no mundo estão os acidentes de trânsito. Eles também trazem grandes consequências à saúde pública, uma vez que, em muitos casos, deixam graves sequelas com implicações físicas e psicossociais nos envolvidos. "No Brasil, os acidentes de trânsito apresentam custos sociais, ambientais, psicológicos e uma alta demanda de leitos hospitalares, além das faltas relacionadas ao trabalho, às indenizações e aos gastos materiais que geram" (OSHIRA, 2017b, p. 1).

Oshira (2017b) destaca que no decorrer de um ano nas rodovias federais brasileiras aconteceram 170 mil acidentes de trânsito, gerando um custo de R $\$$ 12,3 bilhões. Destes gastos, $64,7 \%$ estão relacionados às vítimas dos acidentes, devido aos atendimentos em hospitais, à perda de produção relacionada às lesões e também morte, e 34,7\% referem-se aos danos materiais nos veículos, à perda das cargas e, também, aos gastos com remoção. Já o levantamento feito nas rodovias federais, estaduais e municipais apresenta que os custos com acidentes chegam a um valor de $\mathrm{R} \$ 45$ bilhões por ano.

Contudo, o comportamento dos motoristas e pedestres no trânsito nada mais é que o reflexo da sociedade em que estão inseridos. Czerwonka (2015) afirma que, para Julieta Arsênio, psicóloga especialista em comportamento de trânsito e diretora do departamento de crimes de trânsito e perícias da Associação Brasileira de Medicina de Tráfego (ABRAMET), as pessoas se comportam no trânsito conforme vivem. Deste modo, as pessoas que são cautelosas levam este comportamento para o trânsito e as que têm o perfil de correr riscos dirigem também de maneira perigosa.

Para tanto, como forma de regular os deslocamentos, são impostas normas e regras para o trânsito, justamente para que seja garantida a integridade dos usuários das vias. Assim, transgredir as regras contribui para as fatalidades no trânsito. Como os pedestres fazem parte do sistema de trânsito, eles também devem seguir o que determina o Código de Trânsito Brasileiro, especialmente no que diz respeito às precauções de segurança. "A percepção de risco pode variar conforme a hora do dia, características do ambiente e o modo de transporte costumeiramente utilizado. Os pedestres percebem maior risco de se envolver em um acidente durante o dia" (TORQUATO; BIANCHI, 2015, p. 135).

Os autores destacam, ainda, que é necessário que os motoristas respeitem a faixa de pedestres e os semáforos, e que os pedestres deixem de atravessar as ruas em qualquer lugar, até entre os carros, e passem a ver a faixa como um lugar preferencial de travessia. Para que isso se torne possível é necessário que as políticas de transporte e de circulação proporcionem o acesso amplo e democrático ao espaço urbano, priorizando os modos não motorizados e coletivos de transporte, de modo socialmente inclusivo e ecologicamente sustentável. "Assim, a disponibilidade de um sistema adequado e seguro para 
pedestres pode otimizar o uso das estruturas e, consequentemente, a segurança de todos os usuários" (ARIOTTI, 2015, p. 171).

Na visão de Matta, Vasconcellos e Pandolfi (2010), a questão da falta do cumprimento das leis, tanto por parte dos condutores quanto por parte dos pedestres, está relacionada ao prestígio e ao poder de liberdade que o carro oferece aos seus usuários, fazendo com que os pedestres se tornem vítimas desse espaço, onde o carro deixa de ser um instrumento de locomoção para se tornar um símbolo de superioridade social. "Na qualidade de pedestres e de ciclistas, os usuários do espaço público sentem-se agredidos, inferiorizados e subordinados à lógica selvagem e agressiva do trânsito" (MATTA, VASCONCELLOS, PANDOLFI, 2010, p. 69).

Dessa forma, no mundo moderno, o carro é considerado como um instrumento de liberdade e de autonomia. "Ele iguala e produz a onipotência de uma limitada mobilidade" (MATTA; VASCONCELLOS; PANDOLFI, 2010, p. 83). Portanto, percebe-se que, atualmente, o carro é um objeto de desejo e um instrumento de ascensão social e, como tal, não faz parte do mundo real dos indivíduos iguais que têm o direito de transitar nas ruas de modo consciente. Este é o dilema destacado pelos autores. E, por meio desta consideração, é possível entender a propagação, cada vez mais crescente, de emoções e sentimentos negativos entre os motoristas, como o estresse, a agressividade e a impaciência.

Por outro lado, no Brasil, acredita-se que os problemas no trânsito sempre estão relacionados aos fatores externos, tais como a falta de estrutura adequada. Na verdade, é necessário que tanto motoristas quanto pedestres tenham uma visão democrática das regras e da necessidade de sua obediência para que uma sociedade de iguais possa funcionar. Então, mais do que ouvir, criticar e vociferar, "falta internalizar o respeito e a obediência à lei em função do Outro - do concidadão que conosco compartilha, como um igual, do mesmo espaço público -, e não apenas pela lei em si ou pela autoridade que a representa" (MATTA, VASCONCELLOS, PANDOLFI, 2010, p. 91).

Segundo os autores, a sociabilidade e a sensibilidade que oscilam entre hierarquias e igualdade, holismo e individualismo, produzem uma invisibilidade crônica, seja dos indivíduos, seja das leis. Entre o respeitar e o obedecer há um contraste que ainda não foi compreendido pela sociedade. É preciso que se entenda que: "o passo decisivo para uma democracia implica demonstrar o viés aristocrático e hierárquico que permeia o sistema de modo oculto ou implícito, mas que está pronto a se manifestar em qualquer situação" (MATTA, VASCONCELLOS, PANDOLFI, 2010, p. 102).

Assim, os autores fazem referência a situações de injustiça e crueldade que ocorreram ou que foram impostas a alguém e deixam claro que, quando os cidadãos saem de casa, estão preparados para tudo, sem se darem conta da insensatez e selvageria que toma conta das ruas, onde o carro é um dos principais meios de status e opressão. Por isso, Czerwonka (2015), destaca 
que ser consciente, saber o que se está fazendo e perceber os deslizes é o comportamento ideal no trânsito. Todos os indivíduos têm algumas imperfeições que precisam ser reconhecidas de antemão para que possam ser realizadas ações consideradas ideais e que tornam viável o trajeto de forma adequada no trânsito.

Dessa forma, como citam Neto e Günther (2015), quando as pessoas comentem infrações de trânsito, precisam assumir o risco de sofrer as consequências destes atos. No entanto, é comum que estas apresentem argumentos e fatos para justificarem os comportamentos. Assim, de um modo geral, a intenção e a percepção, que fundamentam e justificam os atos, servem de base para compreender o que leva as pessoas a adotarem atitudes inadequadas. Para tanto, cabe estudar as questões comportamentais dos motoristas que podem ser arriscadas no que se refere ao tráfego, já que o fator humano é um dos principais causadores de acidentes no Brasil.

Neste sentido, de acordo com a Associação Brasileira de Prevenção dos Acidentes de Trânsito (FATORES..., 2017), existem diferentes níveis de fatores comportamentais que podem incidir em acidentes de trânsito, incluindo a subestimação do risco por parte dos motoristas e a maneira como isto se manifesta, que pode ser através de ultrapassagens arriscadas, manobras de risco ou alta velocidade, por exemplo. Dentre as causas que levam ao comportamento de risco, a Associação destaca: a desatenção, o cansaço, o consumo de álcool e, também, as deficiências de visão, de audição e de motricidade.

Além destas causas, Oshira (2017a) apresenta outros comportamentos de motoristas que representam graves riscos no trânsito: o excesso de confiança; a falta de atenção, a fadiga do condutor, o excesso de velocidade; a pressão do tempo; a distância entre os veículos na rodovia e a ultrapassagem arriscada. Considerando estas causas apresentadas pelos autores, serão discorridos a seguir alguns dos comportamentos considerados como os mais arriscados que concorrem para a ocorrência de acidentes de trânsito.

\section{$2.2 \mathrm{O}$ excesso de confiança do motorista}

No que se refere ao excesso de confiança do motorista, de acordo com Oshira (2017a), pesquisas mundiais destacam que $80 \%$ dos acidentes ocorrem nas vias que apresentam boas condições de trafegabilidade, $70 \%$ em pistas secas durante o dia e $65 \%$ em pistas molhadas e em estradas retas. Quando se analisam estes números, percebe-se que o excesso de confiança se traduz em desatenção no trânsito.

Deste modo, surge outro fator decorrente do excesso de confiança: a falta de atenção. Em condições normais, o cérebro leva alguns décimos de segundo para registrar as imagens que o ser humano observa, por isso, por mais atentos que o indivíduo esteja, sempre haverá situações em que não é possível observar. Também existe o fato de que depois que se aprende a dirigir, muitas ações se 
tornam automáticas, então, para evitar as colisões, que representam $70 \%$ dos acidentes, atenção e concentração são necessárias no momento de dirigir. Assim, "uma das principais recomendações na condução de um veículo é evitar distrações, para que respostas rápidas e seguras sejam tomadas minimizando os acidentes e seus impactos" (OSHIRA, 2017a, p. 8).

Para a Associação Brasileira de Prevenção dos Acidentes de Trânsito (FATORES..., 2017), a desatenção está ligada a uma viagem longa, a um trajeto diariamente repetido, ao uso do celular, entre outros motivos. Estes fatores fazem com que o motorista seja incapaz de reagir de modo a evitar que ocorra um acidente, sendo esta a principal causa dos acidentes nas rodovias interurbanas.

Ainda conforme a Associação, fatores ligados à desatenção, como um trajeto longo ou repetitivo, podem levar a outro problema recorrente: o cansaço, já que se o motorista ficar sonolento, sua capacidade de reação fica extremamente reduzida. Em relação à fadiga do condutor, "pode parecer inofensivo ficar rapidamente com os olhos fechados, mas caso ocorra uma situação inesperada esse tempo pode ser fundamental para evitar um acidente" (OSHIRA, 2017a, p. 11). Portanto, é fundamental que o motorista durma de sete a oito horas para que o organismo se recupere e não gere a sensação de cansaço e o comprometimento da atenção, da percepção e da concentração ao volante.

\section{$2.3 \mathrm{O}$ excesso de velocidade}

$\mathrm{O}$ excesso de velocidade, por sua vez, incide sobre a frequência e a gravidade dos acidentes que acontecem no trânsito. Especialmente no caso de atropelamentos, a velocidade é determinante, uma vez que é "dela que dependem os tempos de reação do motorista e do pedestre e, obviamente, a violência do choque" (OSHIRA, 2017a, p. 15). Da mesma forma, Torquato e Bianchi (2015) citam que o fator de risco mais importante e que influencia diretamente na chance de sobrevivência do pedestre que se envolve em acidente é a velocidade do veículo. Para eles, se o veículo estiver a $30 \mathrm{~km} / \mathrm{h}$, existe $90 \%$ de probabilidade de que o pedestre sobreviva. Quanto maior a velocidade do carro, mais graves serão os ferimentos.

Em relação ao excesso de velocidade, Ferreira (2006) entende que está associado a questões culturais de status e poder, por isso, apresenta várias facetas. Há propagandas que associam a velocidade ao prazer e à liberdade, além disso, as indústrias automobilísticas estão desenvolvendo carros possantes, que induzem à velocidade para além daquela estabelecida pelas leis do trânsito. Por outro lado, Moraes e Pinto (2011) associam a velocidade à pressa. Para eles, há motoristas que possuem horários determinados para chegar ao destino e, quando percebem que estão atrasados, abusam da velocidade, colocando em risco sua própria vida e as das outras pessoas. 
Para tanto, a pressão do tempo pode ser citada como outro problema que pode influenciar nos acidentes, não somente pela velocidade, mas também porque, se o motorista permite, a pressão que lhe é imposta pode agir sobre seu estado físico e mental, "afetando diretamente sua capacidade de dirigir com segurança, pois o indivíduo estressado apresenta uma direção mais agressiva e reações inadequadas diante de situações de perigo ou tensão" (OSHIRA, 2017a, p. 18).

\subsection{Distância entre veículos}

Outro fator comum nos acidentes de trânsito é o fato do condutor não conseguir desviar ou parar a tempo de evitar a colisão. Por este motivo, há a necessidade premente de que o motorista mantenha uma distância adequada entre os veículos. Para saber a distância correta e segura "é preciso levar em consideração as condições climáticas, condições de via e do veículo, da visibilidade e da capacidade de reação do motorista" (OSHIRA, 2017a, p. 20).

No que se relaciona ao desrespeito com a distância entre os veículos, a Associação Brasileira de Prevenção dos Acidentes de Trânsito (FATORES..., 2017) destaca que este é um erro frequente e grave, que está presente nas colisões traseiras. Quando o motorista fica muito próximo ao veículo que está à frente, fica consideravelmente reduzido o tempo que ele tem para reagir e o acidente torna-se inevitável.

\subsection{Ultrapassagem perigosa}

De acordo com Oshira (2017a, p. 23), são as ultrapassagens indevidas conjugadas ao excesso de velocidade que causam os acidentes mais graves e com várias vítimas. As colisões frontais são exemplos deste tipo de acidente. "Muitos motoristas ignoram a sinalização de ultrapassagem proibida, ultrapassam em situações de pouca visibilidade e alguns confiam demais em sua habilidade como condutor e na potência do veículo, mas nem sempre estas correspondem a tempo" (OSHIRA, 2017a, p. 23).

A Associação Brasileira de Prevenção dos Acidentes de Trânsito (FATORES..., 2017) corrobora com esta afirmação e acrescenta que a ultrapassagem indevida é a principal causa da colisão frontal, sendo que esta ocupa o segundo lugar nos tipos de acidentes com vítimas fatais. Já o abalroamento lateral de sentido oposto está em quarto lugar. Estes dois tipos são responsáveis por $23 \%$ dos acidentes com vítimas fatais, ambos relacionados com as ultrapassagem consideradas perigosas ou arriscadas.

\subsection{Ingestão de bebidas alcoólicas}

Alguns autores consideram como um dos maiores causadores de acidentes a ingestão de bebidas alcoólicas, já que as mesmas afetam 
consideravelmente o reflexo e a coordenação motora. Segundo a Associação Brasileira de Prevenção dos Acidentes de Trânsito (FATORES..., 2017), o consumo de álcool causa muitos efeitos negativos, tais como: a euforia, que leva à sensação de potência e superestimação das próprias capacidades; a diminuição dos reflexos e o estreitamento do campo visual; a alteração da capacidade de avaliação das distâncias e das larguras; e faz, ainda, com que o motorista tenha maior sensibilidade ao deslumbramento.

Da mesma forma, referindo-se ao consumo de drogas, Ferreira (2006) destaca que, quando a pessoa bebe, sua dimensão psíquica é atingida, sendo assim, a capacidade de rendimento do motorista é afetada, fazendo com que ele tenha uma tendência maior de tolerar o risco e tomar decisões perigosas. Por isso, a legislação de trânsito é bastante rigorosa no que se refere ao consumo de bebidas alcoólicas, já que são inúmeros os problemas decorrentes da associação do álcool com a direção de um veículo.

Contudo, cabe destacar que, em relação à Lei Seca e às blitz, os autores Matta, Vasconcellos e Pandolfi (2010, p. 12) afirmam que "qualquer legislação está destinada ao fracasso caso a sociedade que a recebe dela não necessite ou esteja preparada para suas inevitáveis implicações disciplinadoras". Para tanto, surge a necessidade de estudar e analisar a importância da educação voltada para o trânsito desde os primeiros níveis escolares e a adoção de estratégias psicossociais a fim de mudar o cenário atual de acidentes recorrentes devido a fatores substancialmente humanos.

\section{PAPEL DA PSICOLOGIA PARA A REDUÇÃO DE ACIDENTES DE TRÂNSITO}

A forma de conduzir um automóvel está relacionada ao caráter que cada indivíduo possui, visto que o veículo é apenas um elemento de metal e, ao ser conduzido, passa a ter a inteligência, a alma, a sensibilidade e o comportamento de quem o dirige. Portanto, o veículo se apresenta com as características de personalidade de quem o estiver dirigindo (DOTTA A.; DOTTA R., 2002).

De acordo com Souza, Cruz e Wit (2017), foi em meados do século XX, com o aumento da quantidade de veículos transitando e, consequentemente, com a ocorrência de mais acidentes de tráfego, que os psicólogos passaram a se empenhar para definir um perfil ideal para os condutores. "O objetivo era identificar as características de perfil que auxiliassem o reconhecimento de condutores que oferecessem o menor risco possível a si e aos outros participantes do trânsito" (SOUZA; CRUZ; WIT, 2017, p. 84).

Sendo assim, os psicólogos, junto à segurança pública nacional, passaram a ter o papel de fazer uma seleção das pessoas que teriam o privilégio de dirigir, excluindo aqueles que poderiam oferecer riscos à segurança no trânsito. "Este trabalho de avaliação psicológica, ou de seleção dos condutores, firmou-se até os dias atuais se constituindo uma das atividades mais populares 
do psicólogo de trânsito" (SOUZA; CRUZ; WIT, 2017, p. 84). Também marca os esforços científicos da área na busca pelas características que diferenciam os condutores que constituem risco ou segurança no trânsito.

Assim, para Rozestraten (1988), a psicologia é uma área que se preocupa em estudar os comportamentos humanos no trânsito e, também, os processos externos e internos, conscientes ou inconscientes, que são provocados ou alterados. Todos estes estudos são feitos através de métodos científicos válidos, levando em consideração que o comportamento humano compreende um amplo leque de perspectivas, uma vez que trata de qualquer indivíduo no contexto do trânsito: "pessoas de todas as idades, condições socioeconômicas, escolares, profissionais, culturais, com diferentes objetivos e motivações com relação ao trânsito" (SOUZA; CRUZ; WIT, 2017, p. 62).

Conforme Veltec (2017), a psicologia do trânsito é um campo do conhecimento que se preocupa em estudar o comportamento do homem no contexto do trânsito, identificando fatores internos e externos, conscientes e inconscientes que influenciam na ocorrência de acidentes. Também, a psicologia enfatiza os aspectos relevantes voltados aos comportamentos que são adequados no momento de dirigir, tais como: o tempo de reação, a orientação espacial, o processamento da informação e a tomada de decisão, a verificação do equilíbrio entre aspectos da personalidade, especialmente aqueles ligados ao controle emocional, à ansiedade, à impulsividade e à agressividade, bem como a percepção das ações apropriadas ou não ao trânsito. Sendo assim, a avaliação psicológica para o trânsito deve concentrar-se não somente nos testes que avaliam as informações, mas, também, no comportamento e na subjetividade.

Ainda de acordo com Veltec (2017), é necessário lembrar que existem traços de personalidade que se relacionam aos comportamentos impulsivos, que são capazes de fazer com que a pessoa pratique direção perigosa, seja agressiva, irresponsável, tenha intolerância a frustrações, seja impulsiva e adote atitudes que possam facilitar a maior ocorrência de acidentes no trânsito.

Por outro lado, Günther e Neto (2015) descrevem que a relação entre o comportamento da pessoa e o ambiente de trânsito é amplamente investigada pela psicologia ambiental, que estuda a relação recíproca entre as pessoas e o ambiente. "A principal premissa é, portanto, que a interação indivíduoambiente se constitui por uma relação recíproca, de retroalimentação contínua, tornando-se imperceptível a primazia do indivíduo sobre o ambiente e viceversa" (GÜNTHER; NETO, 2015, p. 32).

Esta abordagem é importante para analisar o comportamento humano no trânsito, uma vez que ele decorre do fato de que as ações dos motoristas, dos ciclistas e demais usuários afetam e são afetadas pelos elementos físicos e sociais que estão dispostos neste ambiente. Inclusive "as modificações introduzidas no ambiente para acomodar os diferentes modos de transporte afetam diretamente o comportamento humano" (GÜNTHER; NETO, 2015, p. 32). Assim, a psicologia ambiental torna possível a investigação sobre a forma 
que a infraestrutura de transporte influencia a escolha do modo de transporte e oferece um aparato conceitual que contribui significativamente para investigar os acontecimentos comportamentais no trânsito.

É difícil para o psicólogo do trânsito entender um comportamento transgressor sem verificar de que modo as variáveis ambientais contribuíram para que aquela atitude ocorresse. "Da mesma forma, um engenheiro de tráfego pode não compreender os motivos que levaram a um acidente, identificando apenas as características ambientais que contribuíram para a sua ocorrência, negligenciando as possíveis variáveis comportamentais nessa situação" (GÜNTHER; NETO, 2015, p. 48).

Portanto, cabe enfatizar que a psicologia ambiental é voltada à resolução de problemas do cotidiano, mas sempre deve estar integrada com as outras ciências, para que se torne possível aplicar seus preceitos ao comportamento e aos eventos que acontecem no ambiente do trânsito.

Neto e Günther (2015) entendem, ainda, que algumas teorias da psicologia social buscam explicar mecanismos psicológicos subjacentes ao ato de tentar justificar as atitudes transgressivas. Assim, a teoria da atribuição da causalidade sugere que as pessoas têm uma tendência de explicar e atribuir causas ao comportamento. E a teoria social cognitiva, que foi desenvolvida por Bandura em 1977 destaca que as pessoas comportam-se de acordo com aquilo que pensam ser certo ou errado. "Esse referencial considera que há uma tendência de as pessoas se comportarem de maneira que lhes traga satisfação pessoal, evitando violar seus padrões morais, pois isso faria que desaprovassem a si mesmas" (NETO; GÜNTHER, 2015, p. 235).

Na verdade, a psicologia, desde o início de sua constituição, visa encontrar soluções para as questões da mobilidade humana. Desde o século XIX, os psicólogos, devido à questão da mobilidade, voltaram sua atenção para os diferentes campos de conhecimento, ampliando o leque de abrangência dos estudos. Assim, segundo Souza, Cruz e Wit (2017), na atualidade, as diferentes áreas da psicologia e mobilidade humana, desde as mais amplas até as mais específicas, procuram orientar e direcionar as discussões para a humanização nos processos de circulação humana. E, uma das principais vertentes que buscam resultados eficazes para uma humanização no trânsito é a educação, sendo que esta pode trazer contribuições fundamentais para a redução de fatores comportamentais nocivos no trânsito.

\subsection{Educação para o trânsito}

Para Czerwonka (2015), Julieta Arsênio acredita que a educação para a o trânsito é o caminho mais eficiente e barato para reduzir os acidentes, por isso não bastam campanhas pontuais, como as que acontecem na Semana Nacional do Trânsito. A educação para o trânsito deve ser uma disciplina escolar, como já 
acontece em outros países. É preciso que desde a infância se crie uma cultura de que as regras devem ser respeitadas, tanto pelo motorista quanto pelo pedestre.

$\mathrm{Na}$ verdade, no Brasil existem políticas referentes à educação no trânsito, como a Lei $\mathrm{n}^{\circ}$ 9.503, de 23 de novembro de 1997, que institui o Código de Trânsito Brasileiro, especialmente no capítulo VI, art. 76, que trata sobre a educação para o trânsito, determinando a participação da sociedade. Assim, a educação para o trânsito deve ser promovida desde a Educação Infantil até o Ensino Superior, através de planejamento e ações coordenadas entre os órgãos e entidades do Sistema Nacional de Trânsito e de Educação, da União, dos Estados, do Distrito Federal e dos Municípios, nas respectivas áreas de atuação.

A mesma lei prevê que o Ministério da Educação e do Desporto, mediante proposta do Contran e do Conselho de Reitores das Universidades Brasileiras, diretamente ou mediante convênio, promova um currículo interdisciplinar com conteúdo programático sobre segurança de trânsito. Esta ação visa a adoção de conteúdos relativos à educação para o trânsito nas escolas de formação para o magistério e o treinamento de professores e multiplicadores, bem como a criação de corpos técnicos interprofissionais para levantamento e análise de dados estatísticos relativos ao trânsito.

Neste mesmo sentido, o Ministério das Cidades, através do Conselho Nacional de Trânsito, aprovou a Resolução no 166, de 15 de setembro de 2004, que dispõe sobre as diretrizes para a Política Nacional de Trânsito. Esta aborda a educação para o trânsito e destaca, em seu item 2.1.2, que a educação para o trânsito ultrapassa a mera transmissão de informações, uma vez que traz como foco o ser humano e trabalha com a possibilidade de mudança de valores, comportamentos e atitudes. Além disso, não se limita a eventos esporádicos e não permite ações descoordenadas, pressupondo um processo de aprendizagem continuada. "A educação para o trânsito inclui a percepção da realidade e a adaptação, assimilação e incorporação de novos hábitos e atitudes frente ao trânsito - enfatizando a corresponsabilidade do governo e sociedade, em busca da segurança e bem-estar" (BRASIL, 2004, p. 76).

Assim, nota-se que já existem políticas públicas voltadas para a educação no trânsito. Contudo, neste sentido, destaca-se a importância de uma educação contínua elaborada segundo diretrizes da psicologia, em consonância com profissionais da área, a fim de que se firmassem importantes medidas para a conscientização da necessidade de novos hábitos e atitudes de responsabilidade para maior segurança no trânsito. Isso aplicado em todos os níveis de ensino conforme as características de cada grau de formação, considerando estudos psicológicos voltados para estes. Dessa forma, por exemplo, nas séries iniciais seriam aplicadas técnicas de ensino adequadas para a aprendizagem de crianças e, em contrapartida, no ensino superior as metodologias seriam mais aprofundadas e efetivas para a educação no trânsito.

Também, Cristo (2012) destaca que a disciplina fundamental para ações de intervenção preventiva para um trânsito mais seguro é a psicologia, uma 
vez que o fator humano corresponde a $90 \%$ dos acidentes. A maioria dos psicólogos do trânsito no Brasil trabalha na avaliação psicológica de motoristas no processo de aquisição da carteira nacional de habilitação, de renovação ou de mudança de categoria, quando for o caso, bem como na realização de pesquisas aplicadas, que visam diagnosticar e sugerir medidas para resolver problemas. Segundo este autor, todas as intervenções realizadas pelo psicólogo do trânsito pretendem colaborar com a qualidade de vida das pessoas, ajudando a promover a segurança viária ou o transporte sustentável e democrático.

\subsection{Resultados e discussões}

Como visto, há diversas características e fatores relacionados ao comportamento humano que podem causar sérios riscos de acidentes de trânsito, e a psicologia pode trazer inúmeras contribuições no sentido de possibilitar mais harmonia e segurança no trânsito. Para tanto, a fim de compreender os resultados obtidos através da pesquisa bibliográfica realizada, cabe citar as características e discussões dos principais artigos e livros analisados e, após, apresentar as considerações e resultados encontrados.

Tabela 1 - Características dos artigos publicados no período de 2010 a 2017.

\begin{tabular}{|c|l|}
\hline ANO E AUTOR(ES) & \multicolumn{1}{c|}{ TíTULO E OBJETIVO(S) } \\
\hline 2012 & $\begin{array}{l}\text { Título: Psicologia e trânsito: reflexões para pais, educadores } \\
\text { e [futuros] condutores. } \\
\text { Objetivo: Averiguar a importância da psicologia não apenas } \\
\text { como forma de avaliação psicológica dos condutores, } \\
\text { mas também para o preparo e a formação dos motoristas, } \\
\text { contribuindo para o fortalecimento da harmonia no trânsito. }\end{array}$ \\
\hline 2015 & $\begin{array}{l}\text { Título: Comportamento no trânsito: uma perspectiva da } \\
\text { psicologia ambiental. } \\
\text { Objetivo: Estudar os elementos físicos e sociais que podem } \\
\text { interferir de forma negativa nas ações dos motoristas, já } \\
\text { que o ambiente e os fatores psicossociais podem afetar o } \\
\text { comportamento adotado no trânsito. }\end{array}$ \\
\hline Günther e Neto \\
\hline Matta, Vasconcellos e \\
Pandolfi & $\begin{array}{l}\text { Título: Fé em Deus e pé na tábua: ou como e por que o } \\
\text { trânsito enlouquece no Brasil. } \\
\text { Objetivo: Averiguar a relação estabelecida entre o motorista } \\
\text { e seu veículo, avaliando a importância do cumprimento da } \\
\text { legislação de trânsito e do respeito entre os cidadãos para } \\
\text { que seja possível estabelecer uma ordem no trânsito. }\end{array}$ \\
\hline
\end{tabular}




\begin{tabular}{|c|l|}
\hline ANO E AUTOR(ES) & \multicolumn{1}{|c|}{ TÍTULO E OBJETIVO(S) } \\
\hline 2017 & $\begin{array}{l}\text { Título: Riscos comportamentais que causam acidentes de } \\
\text { trânsito. } \\
\text { Objetivo: Estudar os principais riscos que podem causar } \\
\text { acidentes de trânsito voltados para o fator humano, } \\
\text { analisando os elementos internos e externos que podem } \\
\text { afetar o motorista durante a condução de um veículo e que } \\
\text { podem acarretar em acidentes. }\end{array}$ \\
\hline 2017 & $\begin{array}{l}\text { Título: Diretrizes para o trabalho do psicólogo do trânsito no } \\
\text { ambito das políticas públicas. } \\
\text { Objetivo: Analisar o papel que o psicólogo pode } \\
\text { desempenhar no sentido de definir o perfil ideal de condutor } \\
\text { como forma de reduzir a quantidade de acidentes de trânsito } \\
\text { em decorrência do fator humano. }\end{array}$ \\
\hline 2017 & $\begin{array}{l}\text { Título: Fatores humanos de risco. } \\
\text { Objetivo: Avaliar os fatores comportamentais que podem } \\
\text { incidir sobre acidentes de trânsito na visão da Associação } \\
\text { Brasileira de Prevenção dos Acidentes de Trânsito, que elenca } \\
\text { as principais causas e problemas que podem ser considerados } \\
\text { altamente de risco no que se refere ao tema. }\end{array}$ \\
\hline Vias Seguras
\end{tabular}

Fonte: A autora (2018).

A grande maioria dos acidentes de trânsito que acontecem na atualidade são decorrentes de falha humana, cerca de $90 \%$. Dessa forma, o autor Oshira (2017a), propôs-se a estudar quais os riscos relacionados ao comportamento dos motoristas que mais poderiam causar acidentes. Entre eles, o autor citou sete dos principais: excesso de confiança do motorista, falta de atenção, fadiga do condutor, excesso de velocidade, pressão do tempo, distância entre veículos e ultrapassagem perigosa.

Da mesma forma, também a Associação Brasileira de Prevenção dos Acidentes de Trânsito, de acordo com dados do site Vias Seguras (FATORES..., 2017), apontou outros fatores que podem ser considerados como de risco, como a subestimação do risco, manobras arriscadas, a desatenção, o cansaço e, talvez o mais polêmico atualmente, o consumo de álcool. Neste sentido, outros autores estudados defendem a necessidade de políticas públicas e legislações voltadas para a área, buscando, através dessas ações governamentais, reduzir a quantidade de acidentes no País.

Com isso, Matta, Vasconcellos e Pandolfi (2010) acrescentam à pesquisa o fato de que as políticas públicas são efetivamente importantes no que se refere à questão do trânsito, contudo, também são necessárias mudanças substanciais na postura dos motoristas e pedestres nos dias de hoje. Isso porque, os resultados só serão verificados no trânsito quando a legislação for seguida de forma efetiva e quando os cidadãos passarem a perceber o trânsito 
como um espaço público em que o outro deve ser respeitado. Somente no momento que todos perceberem que as consequências de seus atos podem estar desrespeitando o espaço do outro é que será possível alcançar um espaço harmônico e equilibrado no trânsito brasileiro.

A partir disso, surge o papel da psicologia na questão da convivência e da postura dos condutores no trânsito. Para contribuir sobre esta questão, os autores Souza, Cruz e Wit (2017) trazem dados importantes, como o fato de que a psicologia atualmente já contribui para reduzir os riscos no trânsito ao realizar uma avaliação psicológica dos futuros condutores, selecionando apenas os que não apresentam riscos. No entanto, afirmam que a psicologia pode contribuir em diversos outros sentidos, já que é uma área que pode estudar e analisar o comportamento humano e sua interferência no trânsito, buscando avaliar todos os processos, tanto externos quanto internos, que incidem sobre as ações dos condutores.

Neste sentido, Günther e Neto (2015) apontam que este tipo de estudo é realizado através da psicologia ambiental, e que esta é fundamental para compreender todos os fatores que incidem sobre o comportamento humano, estabelecendo uma relação entre as pessoas e o ambiente em que estão inseridas. Este tipo de estudo é fundamental no que se refere ao trânsito, pois, como visto, o fator humano é o principal causador de acidentes atualmente.

Por outro lado, Cristo (2012) afirma que tão importante quanto a aplicação de uma legislação voltada para o trânsito, são as ações preventivas, voltadas para a educação no trânsito. E a psicologia pode atuar fundamentalmente nesta área, já que compreende os fatores comportamentais de risco. Para o autor, sabe-se que a educação para o trânsito, no Brasil, como é praticada nos centros de formação de condutores, pode ser rotulada de educação para passar na prova do Detran, além disso, muitos órgãos de trânsito dos estados, que atuam junto às escolas regulares, têm resumido seu trabalho a palestras sobre como tirar a habilitação, sem explicar aos jovens as consequências que as ações impensadas no trânsito podem trazer para elas e para os outros.

Ademais, tanto nos centros de formação de condutores quanto nas escolas, os profissionais também não explicam os porquês da existência de certas normas que parecem, à primeira vista, restringir os direitos e a liberdade dos cidadãos. Deste modo, há a percepção distorcida "de que leis e resoluções de trânsito existem apenas para beneficiar financeiramente alguns setores do mercado, nossos jovens tornam-se transgressores conscientes, contribuindo para a desarmonia coletiva que experienciamos no tráfego das cidades" (CRISTO, 2012, p. 114).

Dessa forma, o autor sugere que seja fundamentado e facilitado, com urgência, o trabalho de professores e instrutores de trânsito, disponibilizando conhecimentos e produzindo materiais que estimulem o debate, em sala de aula, dos diversos temas relacionados à segurança no trânsito. Com isto, notase que o papel da psicologia para a promoção da segurança no trânsito pode 
ir muito além da seleção dos condutores nos centros de habilitação, já que possibilita incluir também o preparo de metodologias de ensino e a participação no processo de educação para o trânsito tanto nas escolas regulares quanto na formação de condutores.

\section{CONCLUSÃO}

Evidenciou-se, por meio desta pesquisa, que o fator humano é o responsável por $90 \%$ das causas dos acidentes de trânsito. Deste modo, para prevenir acidentes no trânsito é importante que o condutor esteja constantemente instruído e preparado para conduzir da melhor forma possível, para saber como evitar e agir diante de fatores de riscos que aumentem a possibilidade de acidentes.

Demonstrou-se que, apesar de existir uma legislação que regulamenta e institui a educação para o trânsito, os acidentes fazem vítimas a todo o instante no País e representam um importante peso econômico e social, que é arcado por toda sociedade. Portanto, uma vez que a maior parte dos acidentes acontece por imprudência dos motoristas, é necessária a conscientização e a mudança de comportamento de todos sobre a responsabilidade no trânsito.

Para evitar acidentes envolvendo pedestres é necessário implementar a obrigatoriedade de preferência da faixa de pedestres e fiscalizar semáforos, para que os motoristas não violem esta regra. Como as travessias para pedestres representam pontos cruciais na operação de um sistema de transportes, devem ser utilizadas adequadamente, a fim de contribuir para o aumento da segurança e diminuir os desvios de atenção dos motoristas.

Por outro lado, a psicologia ambiental, interligada às outras ciências, pode aplicar seus preceitos ao comportamento humano e aos diversos eventos que acontecem diariamente no ambiente do trânsito, contribuindo significativamente para a investigação e a compreensão da relação neste mecanismo. No que se refere às justificativas para as infrações, percebeu-se que elas são utilizadas pelos condutores com o objetivo de tornar a infração aceitável, na verdade, os argumentos usados ajudam a aprofundar os estudos da psicologia sobre comportamento humano no trânsito.

Portanto, evidenciou-se que as diferentes áreas da psicologia e mobilidade humana, desde as mais amplas até as mais específicas, estão orientando e direcionando as discussões para humanizar os processos de circulação humana. Além disso, o caráter multidisciplinar do trânsito exige que se tracem diferentes focos de estudo e campos de atuação, envolvendo diversas ciências.

Acredita-se que os acidentes e as mortes que acontecem no trânsito são atribuídos à vários fatores e, não menos preocupante, à cultura e à educação limitada dos condutores e o não investimento no comportamento seguro. Assim, o expressivo número de acidentes de trânsito, com jovens recém-habilitados, 
faz com que os profissionais da psicologia se questionem sobre suas atuações nos CFCs, que hoje se resumem às avaliações, e nas escolas regulares.

Considerando que o curso para os candidatos de primeira habilitação obedece à estrutura curricular básica, conforme a Resolução $\mathrm{n}^{\circ} 285$ de julho de 2008, do Conselho Nacional de Trânsito - CONTRAN e, nesta, não consta nenhuma abordagem didático-pedagógica, que abrange a psicologia, levantase a questão de por que o psicólogo não atua junto ao referido curso.

Os acidentes e infrações envolvendo os condutores instigam a psicologia a pensar em uma atuação no sentido de fazer este público pensar em relação à educação, responsabilidade e ao valor à vida. Acredita-se que, através desses levantamentos e de uma análise, pode-se pensar na atuação do psicólogo junto aos cursos teóricos ministrados nos CFCs e nas salas de aula em todos os níveis de ensino, contribuindo com técnicas psicológicas para tornar possíveis as mudanças de comportamento no trânsito brasileiro.

Por fim, cabe citar que a principal dificuldade enfrentada durante a pesquisa foi de encontrar materiais bibliográficos atualizados sobre o papel da psicologia na formação de alunos e condutores, já que ainda são poucos teóricos que abordam o assunto. Assim, como sugestão, vale colocar que sejam feitos mais estudos na área, de inserir conteúdos de psicologia nos cursos teóricos de formação de condutores e também no sentido de prevenção de acidentes voltados para os principais fatores de riscos.

\section{REFERÊNCIAS}

ARIOTTI, Paula. Padrão de comportamento de pedestres em travessias semaforizadas: um modelo conceitual. In: GÜNTHER, Hartmut et al. Pesquisa sobre comportamento no trânsito. São Paulo: Casa do Psicólogo, 2015.

BRASIL. Lei n. 9.503, de 23 de setembro de 1997. Código de Trânsito Brasileiro. Disponível em: <http://www.planalto.gov.br/Ccivil_03/leis/L9503.htm>. Acesso em: 27 mar. 2018.

BRASIL. Resolução n. 166, de 15 de setembro de 2004. Política Nacional de Trânsito. Disponível em: <http://www.lex.com.br/doc_360352_RESOLUCAO_N_166_DE_15_ DE_SETEMBRO_DE_2004.aspx>. Acesso em: 27 mar. 2018.

CRISTO, Fábio de. Psicologia e trânsito: reflexões para pais, educadores e [futuros] condutores. São Paulo: Casa do Psicólogo, 2012.

CZERWONKA, Mariana. Comportamentos de risco podem tornar o trânsito a $5^{\text {a }}$ causa de morte. Portal do Trânsito, Rio de Janeiro, 27 jan. 2015. Disponível em: <http:/ / portaldotransito.com.br/noticias/comportamentos-de-risco-podem-tornar-o-transitoa-5a-causa-de-morte/>. Acesso em: 26 abr. 2018. 
DOTTA, Ático J.; DOTTA, Renata. Acidentes de trânsito: como evitá-los. 4. ed. Porto Alegre: Editora do autor, 2002.

FATORES humanos de risco. Vias Seguras, Rio de Janeiro, 2017. Disponível em: <http://www.vias-seguras.com/os_acidentes/causas_de_acidentes/fator_humano >. Acesso em: 17 abr. 2018.

FERREIRA, Camila C. Acidentes motocicleta-carro: um estudo das representações sociais no trânsito em Goiânia. 2006. 169 f. Dissertação (Mestrado) - Departamento de Psicologia, Universidade Católica de Goiás, Goiânia, 2006.

GIL, Antonio C. Métodos e Técnicas de Pesquisa Social. 6. ed. São Paulo: Atlas, 2008.

GÜNTHER, Hartmut; NETO, Ingrid. Comportamento no trânsito: uma perspectiva da psicologia ambiental. In: GÜNTHER, Hartmut et al. Pesquisa sobre comportamento no trânsito. São Paulo: Casa do Psicólogo, 2015.

MATTA, Roberto da; VASCONCELLOS, João G. M.; PANDOLFI, Ricardo. Fé em Deus e pé na tábua: ou como e por que o trânsito enlouquece no Brasil. Rio de Janeiro: Rocco, 2010.

MORAES, Thiago D.; PINTO, Francinaldo M. O corpo nas atividades em trânsito: condutores profissionais e mobilização do corpo-si. Cadernos de Psicologia Social do Trabalho, São Paulo, v. 14, n. 2, p. 279-294, dez. 2011.

NETO, Ingrid; GÜNTHER, Hartmut. Justificativas de motoristas para infrações de trânsito: uma análise a partir do desengajamento moral. In: GÜNTHER, Hartmut et al. Pesquisa sobre comportamento no trânsito. São Paulo: Casa do Psicólogo, 2015.

NEVES, José L. Pesquisa Qualitativa: Características, usos e possibilidades. Caderno de Pesquisas em Administração, São Paulo, v. 1, n. 3, p. 1-5, 1996.

OSHIIRA, Ana Paula. Riscos comportamentais que causam acidentes de trânsito. São Paulo: Veltec, 2017. E-book. Disponível em: <http://veltec.com.br/static/eBookRiscos-comportamentais.pdf>. Acesso em: 14 mar. 2018.

OSHIIRA, Ana Paula. Como os custos dos acidentes de trânsito estão te afetando diretamente. Veltec, São Paulo, 08 jun. 2017. Disponível em: <https:/ / veltec.com.br/ como-os-custos-dos-acidentes-de-transito-te-afetam-diretamente/?utm_campaign=6_ fluxo_prevencao_-de_acidentes_-_rp2_-_custos_dos_acidentes_de_transito\&utm_ medium =email\&utm_source=RD+Station $>$. Acesso em: 18 mar. 2018.

ROZESTRATEN, R. J. A. Psicologia do trânsito: conceitos e processos básicos. São Paulo: EPU-EDUSP, 1988.

SOUZA, Caroline Z.; CRUZ, Roberto M.; WIT; Paulus A. J. M. Diretrizes para o trabalho do psicólogo do trânsito no âmbito das políticas públicas. In: Manual de Psicologia do Trânsito. São Paulo: NilaPress, 2017. 
TEBALDI, Eliza; FERREIRA, Vinícius R. T. Comportamentos no trânsito e causas da agressividade. Revista de Psicologia da UnC, Mafra, v. 2, n. 1, p. 15-22, 01 dez. 2004.

TORQUATO, Renata J.; BIANCHI, Alessandra S. Uma análise da percepção de risco de pedestres e dos comportamentos de risco de travessia. In: GÜNTHER, Hartmut et al. Pesquisa sobre comportamento no trânsito. São Paulo: Casa do Psicólogo, 2015.

VELTEC. Tecnologia para telemetria e monitoramento de frota com foco na prevenção de acidentes de trânsito e redução dos custos operacionais. 2017. Disponível em: <https://veltec.com.br/>. Acesso em: 15 mar. 2018. 